\title{
Slope Instability at Nablus-Al Bathan Road, Palestinian Territories (Causes, Analysis and Remedy Measurements)
}

\author{
Isam Jardaneh ${ }^{1}$, Sami Hijjawi ${ }^{2}$, George Odeh $^{3}$ \\ ${ }^{1}$ Civil Engineering Department, Faculty of Engineering and Information Technology, An-Najah National University, Nablus, \\ Palestinian Territories \\ ${ }^{2}$ Hijjawi Construction Labs, Nablus, Palestinian Territories \\ ${ }^{3}$ Diyar Consulting Company, Ramallah, Palestinian Territories \\ Email: jardaneh@najah.edu, hcl@palnet.com,diyar@palnet.com
}

How to cite this paper: Jardaneh, I., Hijjawi, S. and Odeh, G. (2021) Slope Instability at Nablus-Al Bathan Road, Palestinian Territories (Causes, Analysis and Remedy Measurements). World Journal of Engineering and Technology, 9, 538-547.

https://doi.org/10.4236/wjet.2021.93036

Received: June 22, 2021

Accepted: July 30, 2021

Published: August 2, 2021

Copyright $\odot 2021$ by author(s) and Scientific Research Publishing Inc. This work is licensed under the Creative Commons Attribution International License (CC BY 4.0).

http://creativecommons.org/licenses/by/4.0/

\begin{abstract}
Nablus-Al Bathan Road which connects Nablus City and Jordan Valley in the West Bank of Palestinian Territories, was widened, reconstructed and rehabilitated in 2009, however, between 2010 and 2012 road defects at several locations were observed. To fix these defects especially at station $2+100$ of the road, soil replacement in the body of the road and big boulders to support the edge of the road were used. Unfortunately, large settlement occurred in the part of the road under maintenance and more sliding and slope instability occurred in the road at station $2+100$ during the remedial measures. Studies were carried out to find the causes of this problem. These included surveying of the area, geotechnical studies (making trial pits, performing geophysical seismic exploration and digging out several boreholes), in addition to slope stability analysis. It was found that the main causes of landslides were types of soils at the site, high slopes, groundwater recharged from rainfall and changing of weights (cut and fill). Remedy measures were suggested to overcome sliding problem based on available resources and local technology.
\end{abstract}

\section{Keywords}

Slope Instability, Landslide, GeoStudio (Slope/w), Remedy Measures

\section{Introduction}

Landslides occur in many places around the world, especially the mountainous areas. They cause great danger to structures and people close to them. Slide or slope failure is a downward and outward movement of a slope that causes failure 
of a mass of soil [1] [2]. Slides or slopes failure are usually caused by excavation, by undercutting at the foot of an existing slope, by gradual disintegration of the structure of the soil, by an increase of the pore water pressure, or by vibration or shock. Secondary causes, such as earthquakes and excavations near the slope, may trigger and activate landslides, especially in areas that had old landslides [1] [2] [3].

Landslides occur when the component of gravity is large enough so that the driving force overcomes the resistance from the shear strength of the soil along the rupture surface [4] [5] [6]. The first signs of landslide are the appearance of surface cracks at the top of the slope perpendicular to sliding movement. These cracks are occasionally filled with water that reduce the strength of the soil and increase lateral pressure that causes sliding [1] [3]. There are different types and processes associated with landslide and slope instability [7].

It is very important and essential to evaluate the stability of slopes in soil, moreover, it is a challenging matter of geotechnical engineering. It had leaded to understand the complex behavior of soils through extensive engineering and research studies carried out in the past 100 year to solve practical engineering problems associated with slope stability. Stability analysis determines whether the given or proposed slope meets the safety requirements regarding shear failure and deformation of the soil mass. The analysis must be made for the worst existing and predicting conditions. It needs knowledge of analytical methods as well as experience and judgment [6] [8] [9] [10]. The stability of the slope is not an easy task [11], it depends on soil stratification, shear strength parameters of soil, seepage through the slope, and the choice of a potential slip surface. The most likely rupture surface is the critical plane that has the minimum factor of safety. All methods used to predict slip surface are designed to calculate the factor of safety. Usually, different slip surfaces are tried for calculations in order to obtain the minimum factor of safety. To make calculations simple, the slip surface is often assumed circular or composed of few straight lines [12].

Nablus-Al Bathan Road east to Nablus City in West Bank of Palestinian Territories that extends to Jordan Valley was widened, reconstructed and rehabilitated in 2009 by Nablus Public Works and Housing Directorate (PWHD-Nablus). In 2010 based on observations by PWHD-Nablus, there were some road defects at this road in several places. Some minor remediation was carried out to fix these defects. In 2011 road defects reappeared at several locations and especially at Station $2+100$. These defects can be described as longitudinal cracks along the eastern side of the road, in addition to initial sliding of this part of the road. In March 2012, PWHD-Nablus attempted to fix these defects at station $2+100$ by replacing the soil and using big boulders to support the road. Unfortunately, large settlement occurred in the part of the road under maintenance and more sliding and slope instability problem occurred in the road at station $2+100$.

Analysis of slope stability for the study location (station $2+100$ ) was carried out to find the causes of sliding using software called GeoStudio (Slope/W) [13]. 
Remedial measure based on supporting the road with retaining wall that will be constructed on rows of deep piles. This method was suggested based on the existing local technology and due to lack of resources.

\section{Description of the Problem}

Nablus Al Bathan site location that suffers instability problems is shown in Figure 1. Typical longitudinal cracks in several locations along the eastern side of the road were noticed yearly, as shown in Figure 2. In 2009 PWHD-Nablus did major rehabilitation to the road, such as widening and reconstruction the road. In March 2012, large longitudinal cracks along the eastern side of the road at
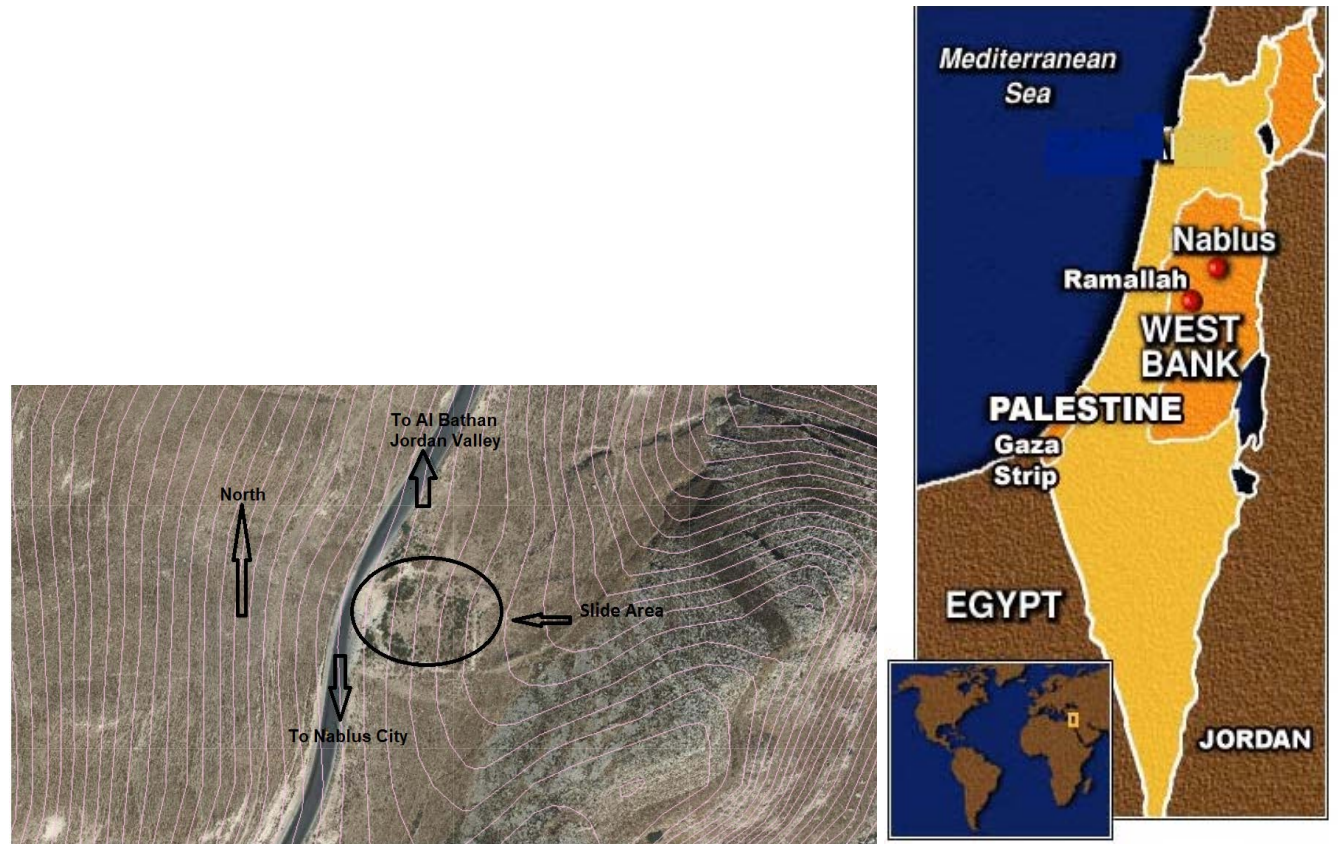

Figure 1. Landslide in eastern side of the road and extended down to the bottom of the valley.

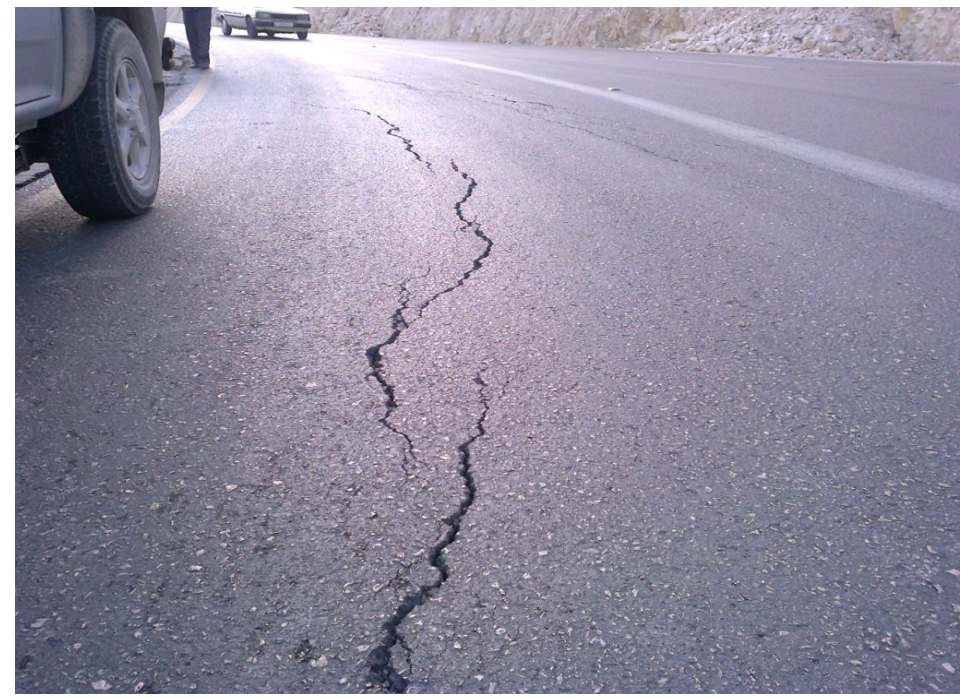

Figure 2. Typical cracks that occurs yearly along Nablus-Al Bathan Road. 
station $2+100$ occurred and this required that PWHD-Nablus to do rehabilitation to this part of the road.

The rehabilitation conducted by PWHD-Nablus at station $2+100$ was replacing the body of the of the road to a depth of about $4 \mathrm{~m}$ by several layers of boulders and base course and supporting the eastern side of the road by big boulders to a depth of about $6 \mathrm{~m}$ below the ground surface. This is shown in Figure 3. During the construction of the remedial measures large settlement and sliding occurred in the eastern part of the road next to the big boulders and extended down to the bottom of the valley, as shown in Figure 4.

\section{Soil Description and Properties of the Study Area}

In order to better understand the causes of landslides and slope instability in the study area at Station $2+100$, it is important to describe soil strata and the conditions of the area. Geophysical exploration was carried out [14], two trial pits were excavated east of the road at the bottom of the valley to a depth of about $7.5 \mathrm{~m}$

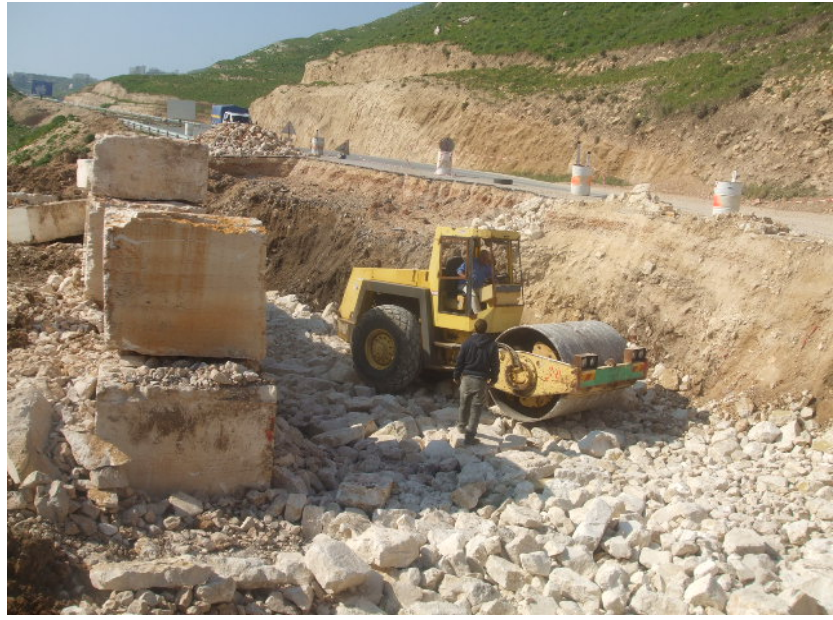

Figure 3. Remedial measures to fix the problem at station $2+100$ in March 2012.
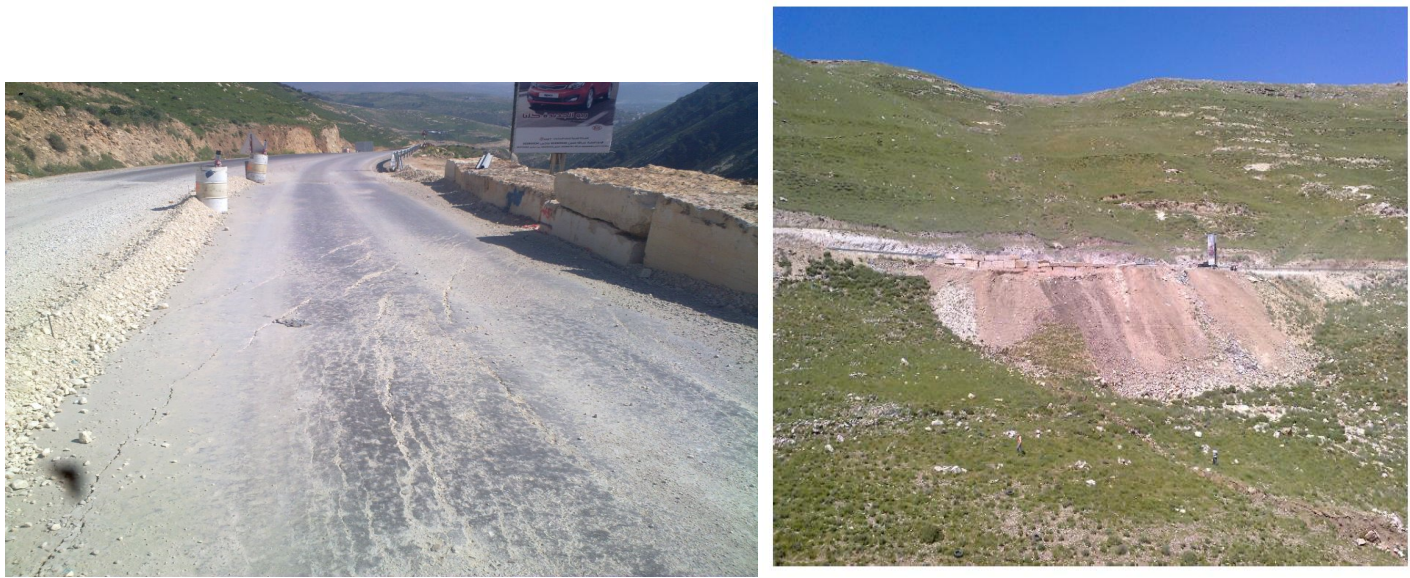

Figure 4. Large settlements occurred in eastern side next to big boulders (left picture) and large landslide occurred and extended to bottom of the valley (right picture) in 2012 during the construction of remedial measures. 
below the existing ground surface, in addition to those 10 boreholes were dug out in the site (east and west of the main road) for depths range between 20 and $30 \mathrm{~m}$ from the existing ground surface. Figure 5 shows the locations of boreholes and the sections that considered in slope stability analysis.

Detailed soil properties and parameters within the depth of each borehole were obtained from soil mechanics laboratory tests. However, these properties were reduced to minimum soil properties and in this case the soil layers were reduced to three layers with minimum soil values as shown in colors as in Figure 6 for section 7-6-10-8 as an example. Table 1 shows the values of soil parameters

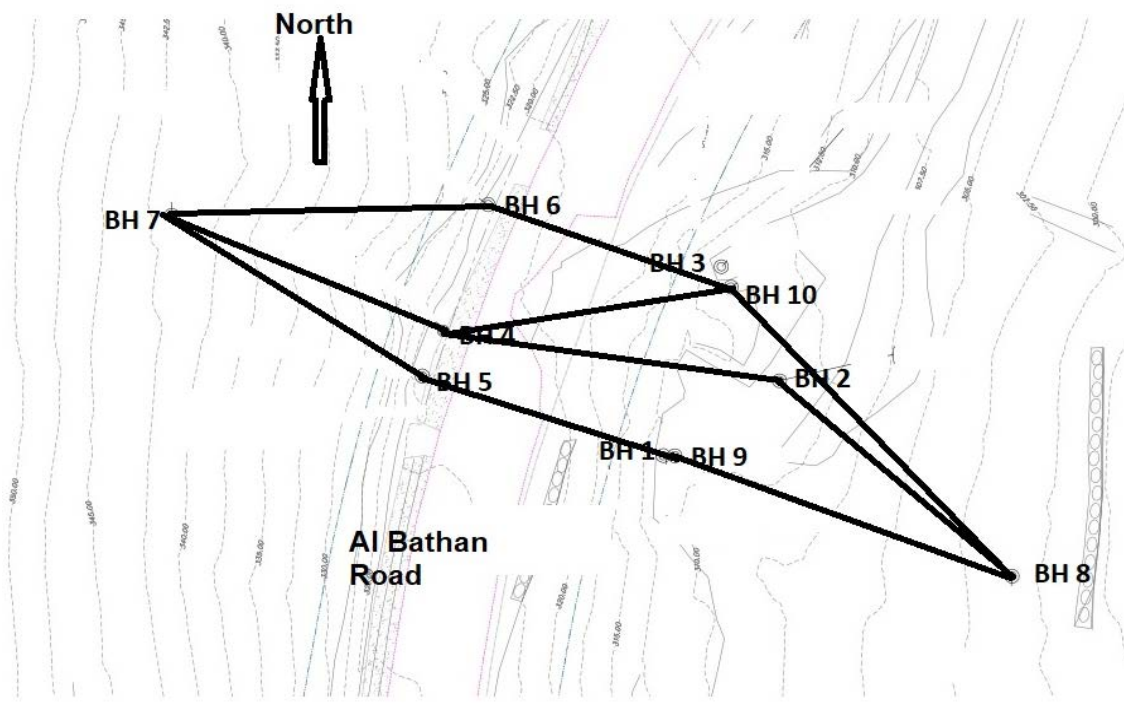

Figure 5. Location of borehole and the four critical sections that used in slope stability analysis, section 7-6-10-8, section 7-4-2-8, section 7-6-10-8 and section 7-4-10-8.

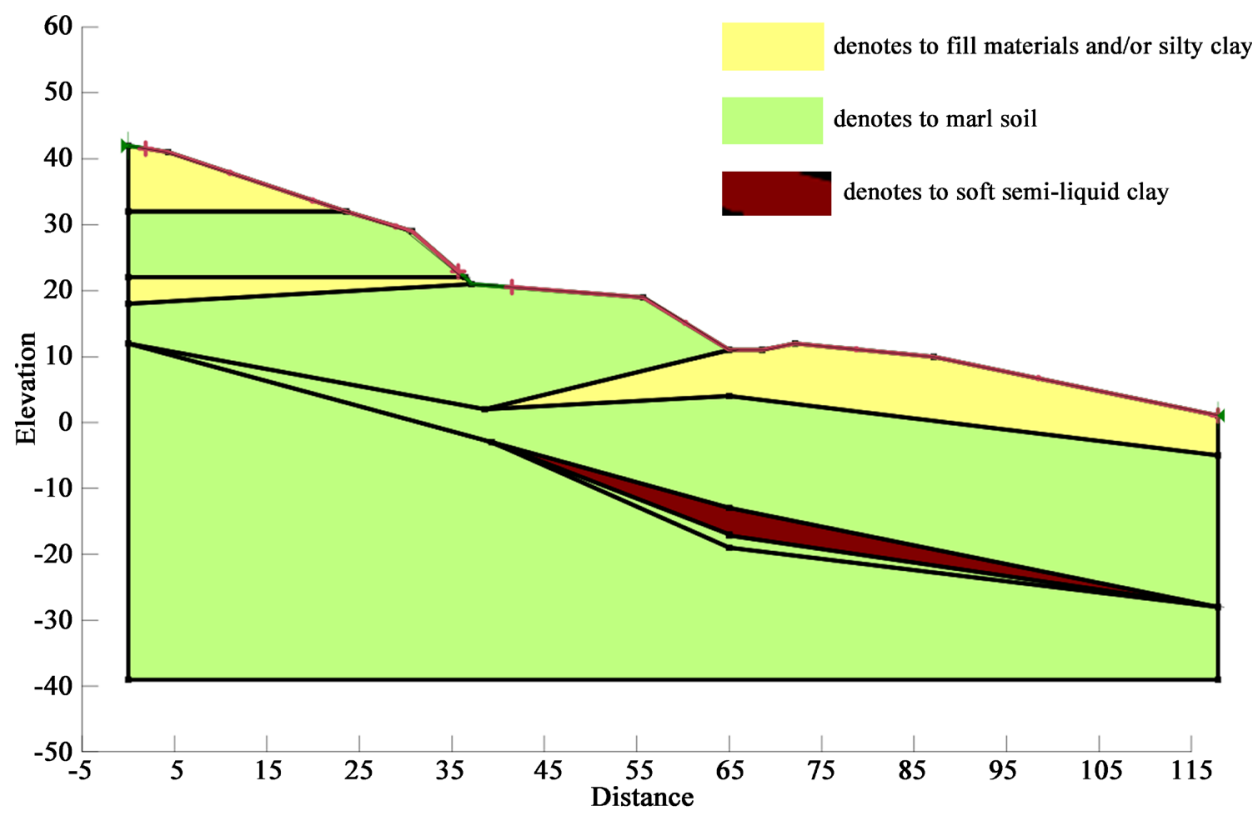

Figure 6. Soil strata as reduced to critical soil properties as in Section 7-6-10-8. 
that used in slope stability analysis. It is important to note that a soft saturated semi-liquid clay layer was found at a depth of about 20 to $23 \mathrm{~m}$ from the ground surface.

\section{Slope Stability Analysis and Results}

The main aim of slope stability analysis is to find the slope that have the minimum factor of safety and the force corresponding to this slope. Slope stability analyses were done for four critical sections that cover the study area. These sections pass through the boreholes as shown in Figure 7 above. They are section 7-6-10-8, section 7-4-2-8, section 7-6-10-8 and section 7-4-10-8. Software called GeoStudio2012 Slope/w [12] was used to carry the analysis. Slope/w is a slope stability CAD software used to compute the factor of safety of earth and rock slopes. Slope/w analyzes simple and complex problems for a variety of slip surface shapes, pore-water pressure conditions, soil properties, analysis methods and loading conditions. However, the analysis method that will be followed in our analysis is Morgenstern-Price method [15].

Table 2 summarizes the slope stability results found using the software GeoStudio Slope/w, it presents the minimum factor of safety and the resisting and activating forces along the slope. Figure 7 and Figure 8 show sample results of slope stability analysis results for section 7-6-10-8.

In general, the factor of safety required for stable slope is 1.5 [11]. It is clear that the site in general suffers slope instability and hence, landslides may occur at any moment above and below the main street alignment. The factor of safety

Table 1. Soil properties that used in slope stability analysis.

\begin{tabular}{cccccc}
\hline Soil Layer No. & Description & $\begin{array}{c}\text { Color of soil in } \\
\text { Slope Stability Analysis }\end{array}$ & $\begin{array}{c}\text { Unit Weight } \\
(\gamma) \mathrm{kN} / \mathrm{m}^{3}\end{array}$ & $\begin{array}{c}\text { Undrained Cohesion } \\
(\mathrm{c}) \mathrm{kN} / \mathrm{m}^{2}\end{array}$ & $\begin{array}{c}\text { Angle of Internal } \\
\text { Friction }\left(\varphi^{\circ}\right)\end{array}$ \\
\hline 1 & Fill materials and/or silty clay & Yellowish & 16 & 25 & 16 \\
2 & Marl soil & Light Greenish & 17 & 7 & 22 \\
3 & Soft semi-liquid clay & Brownish & 15 & 45 & 0 \\
\hline
\end{tabular}

Table 2. Summary results of slope stability analysis.

\begin{tabular}{|c|c|c|c|c|c|}
\hline & Section No. and Description of the Case & $\begin{array}{l}\text { Minimum Factor } \\
\text { of Safety }\end{array}$ & $\begin{array}{l}\text { Total Resisting } \\
\text { Force kN }\end{array}$ & $\begin{array}{l}\text { Total Activating } \\
\text { (Driving) Force kN }\end{array}$ & $\begin{array}{l}\text { Shear Force to be } \\
\text { Resisted by Piles kN }\end{array}$ \\
\hline \multirow{2}{*}{$7-6-10-8$} & Soft Semi-Liquid Layer as Found During Drilling & 1.091 & 678.42 & 621.43 & \\
\hline & Soft Semi-Liquid Layer Extends to Close layer & 0.860 & 5455.5 & 6358.1 & 902.6 \\
\hline \multirow{2}{*}{$7-4-2-8$} & Soft Semi-Liquid Layer as Found During Drilling & 1.043 & 504.86 & 484.73 & \\
\hline & Soft Semi-Liquid Layer Extends to Close layer & 1.028 & 5985.3 & 5820.1 & \\
\hline \multirow{2}{*}{ 7-5-9-8 } & Soft Semi-Liquid Layer as Found During Drilling & 1.213 & 1061.5 & 875.86 & \\
\hline & Soft Semi-Liquid Layer Extends to Close layer & 1.204 & 6464.3 & 5368.6 & \\
\hline \multirow{2}{*}{$7-4-10-8$} & Soft Semi-Liquid Layer as Found During Drilling & 1.025 & 582.39 & 491.55 & \\
\hline & Soft Semi-Liquid Layer Extends to Close layer & 0.90 & 7242.7 & 8018.5 & 775.8 \\
\hline
\end{tabular}




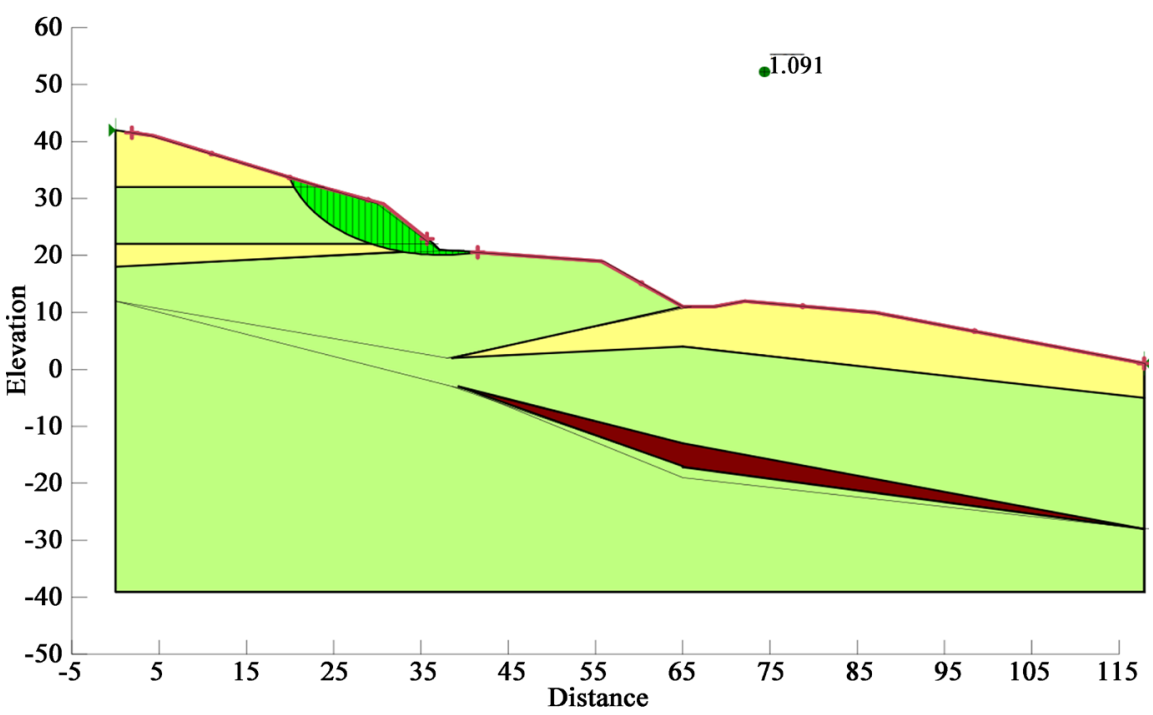

Figure 7. Slope stability analysis for section 7-6-10-8 with Soft Semi-Liquid layer as found during drilling (minimum factor of safety $=1.091$ ).

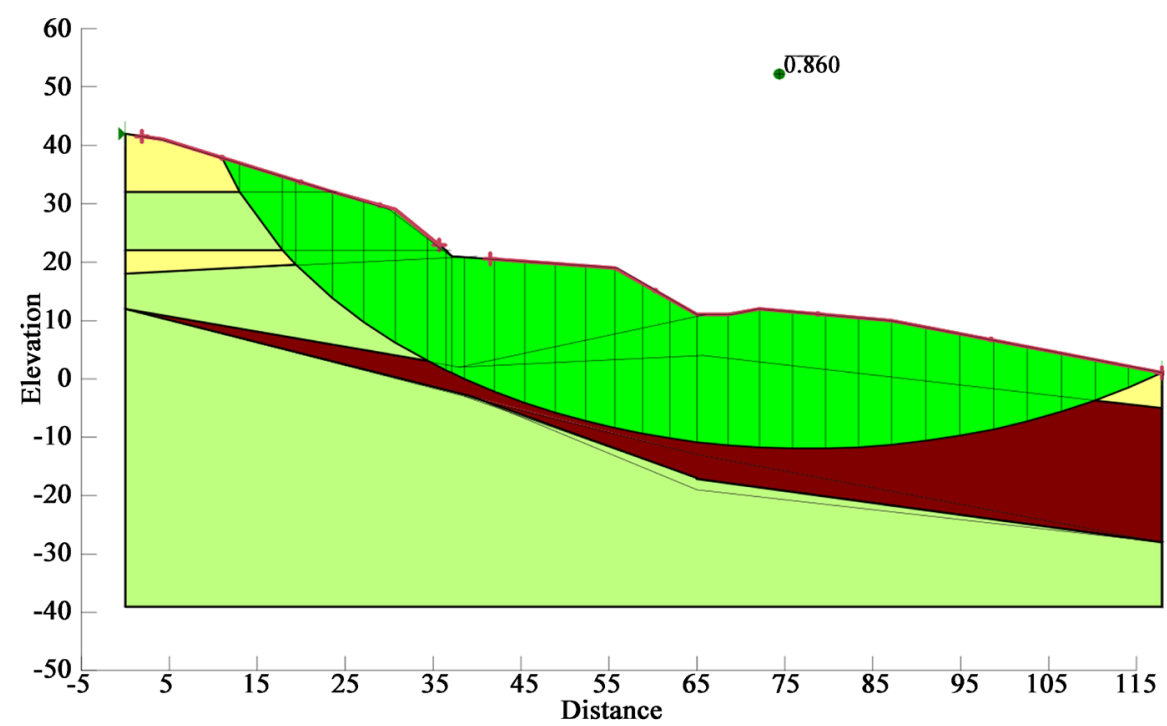

Figure 8. Slope stability analysis for section 7-6-10-8 with Soft Semi-Liquid layer extends to close layer (minimum factor of safety $=0.860$ ).

above the as well as below the main street is well below 1.5. The case becomes worst as the soft semi-liquid layer extends to other layers as expected during winter season.

The results show the resisting force due to shear strength properties of the soil and the driving or activating slope failure due to the soil mass. The difference with appropriate factor of safety should be carried out by a set of piles that will resist this shear force.

Remedy measurements in 2012 by inserting big boulders at the eastern edge of the main street increased the driving force and hence reducing the factor of safety. This is the main reason that sliding was recognized clear at that time. The solution to this problem is to insert piles below the soft semi-liquid layer in or- 
der to improve its property, increase shear resistance and try to eliminate this layer by mixing it with concrete.

\section{Remedy Measurements for Landslides}

Numerous methods can be used to correct landslides [1] [2] [12]. The commonly used correction methods can be divided into the following three main groups. The first one is geometrical methods, which involve the change of the geometrical conditions of a slope by flattening of the slope, removal of the soil or other loads at the top of the slope, and placing pressure berms at the toe of the slope. The second method is hydrological methods, such as a lowering of the groundwater table or a reduction of the water content of the soil. This can be accomplished by surface drains, or drainage galleries, or sand drains. The third method is mechanical methods, which increase the average shear strength of the soil. This method can be done by various techniques, such as, compaction, grouting, rock bolts, piles and sheet piles, and retaining walls. In addition to that land use policy may be considered as a protective measurement especially for sites that had previous landslides.

However, due to limited resources and technology available in our country (Palestinian Territories), the correction measurement for this problem is to insert deep piles that have lengths below the soft semi-liquid layer. The difference of resisting forces and activating forces shown above in Table 2 that produce the factor of safety less than 1 should be resisted by the designed set of piles with an appropriate factor of safety. Figure 9 shows the distribution of the piles with pile cap and retaining wall on top of the pile cap to protect the road at the eastern side. A set of piles are also proposed at the western side of the road to protect the western slope.
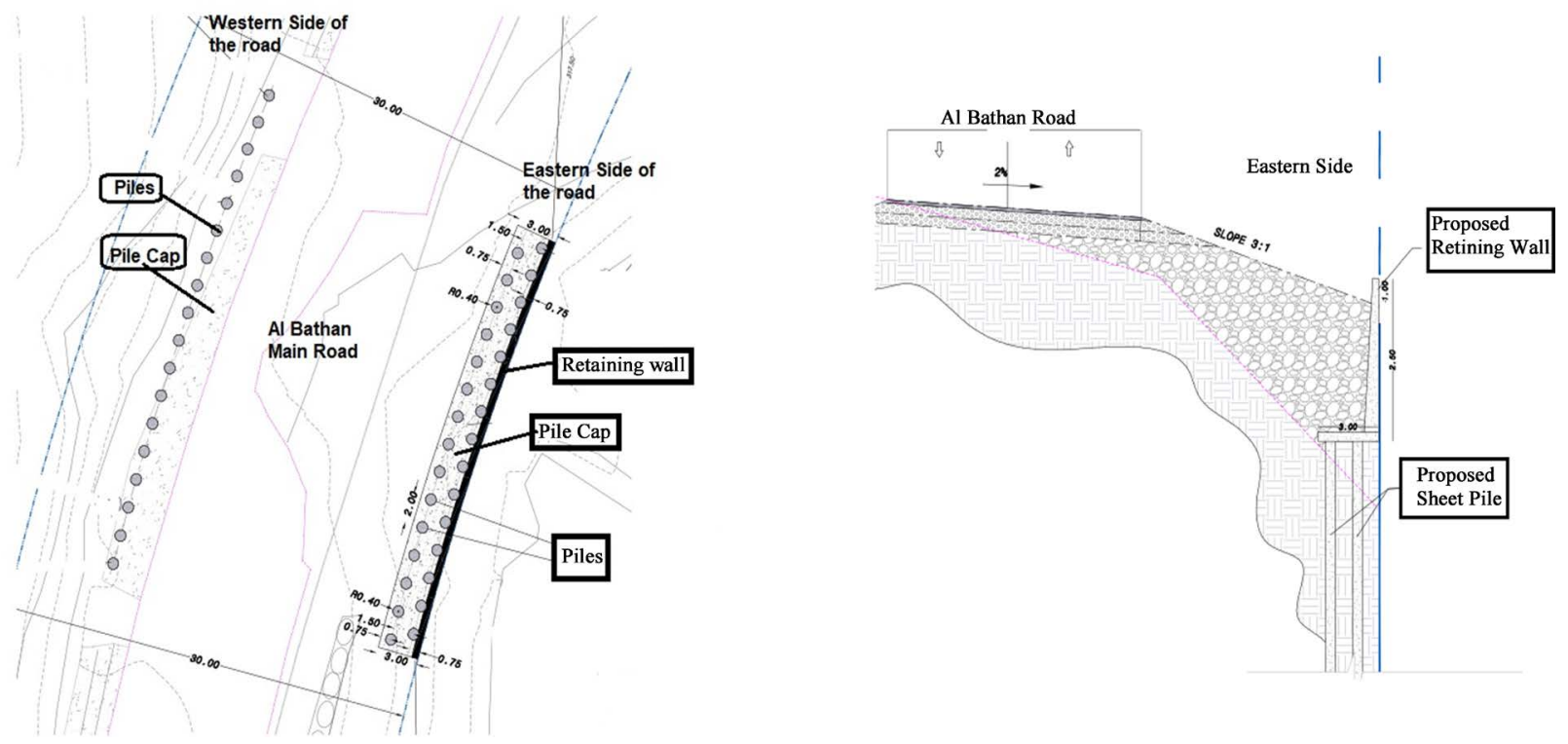

Figure 9. The distribution of the piles with pile cap and retaining wall on top of the pile cap at the eastern side and a set of piles at the western side of the road. 


\section{Conclusions and Recommendations}

Local failures in terms of local landslide may occur in both the western and eastern side of the site, hence causing cracks and settlements in the road. This is due to high unsupported slopes at both sides, complex soil type, there is no strong soil layers at shallow depths and weather conditions.

Recommendations regarding reducing the instability problem in the site are by avoiding no new loads on the top of the slope, such as, new buildings, fill or dump materials, etc., planting the slopes with special types of trees to increase the stabilization of the soil and slopes should be checked on regular basis for any problems and cracks. Cracks find, they should be closed and compacted.

As strategic planning to solve slope instability of Nablus-Al Bathan Road is to search for an alternative new route that should be located on good soil strata. Western and eastern part of the alignments of the road is considered hazardous areas for new structures due to lack of slope stability, hence this zone should be considered as a green area and no construction permits should be allowed for this area.

\section{Conflicts of Interest}

The authors declare no conflicts of interest regarding the publication of this paper.

\section{References}

[1] Fang, H.Y. and Mikroudis, G.K. (1991) Stability of Earth Slopes. In: Fang, H.Y., Ed., Foundation Engineering Handbook, Springer, Boston, 379-409. https://doi.org/10.1007/978-1-4615-3928-5 10

[2] Duncan, J., Wright, S. and Brandon, T. (2014) Soil Strength and Slope Stability. 2nd Edition, John Wiley and Sons, Inc., Hoboken.

[3] Terzaghi, K., Peck, R. and Mesri, G. (1996) Soil Mechanics in Engineering Practice. 3rd Edition, John Wiley and Sons, Inc., New York.

[4] Baker, R. (1980) Determination of the Critical Slip Surface in Slope Stability Computations. International Journal for Numerical and Analytical Methods in Geomechanics, 4, 333-359. https://doi.org/10.1002/nag.1610040405

[5] Nguyen, M. (1985) Determination of Critical Slope Failure Surfaces. Journal of Geotechnical Engineering, 111, 238-250. https://doi.org/10.1061/(ASCE)0733-9410(1985)111:2(238)

[6] Chen, Z. and Shao, C. (1989) Evaluation of Minimum Factor of Safety in Slope Stability Analysis. Canadian Geotechnical Journal, 25, 735-748. https://doi.org/10.1139/t88-084

[7] Cruden, D.M. and Varnes, D.J. (1996) Landslide Types and Processes. In: Turner, A.K. and Schuster, R.L., Eds., Landslides Investigation and Mitigation: Transportation Research Board, Special Report No. 247, US National Research Council, Washington DC, 36-75.

[8] Gue, S.S. and Fong, C.C. (2003) Slope Safety: Factors and Common Misconceptions. BEM Bulletin Ingeniur, 2003, 1-7.

[9] Cheng, Y.M. (2003) Location of Critical Failure Surface and Some Further Studies 
on Slope Stability Analysis. Computers and Geotechnics, 30, 255-267. https://doi.org/10.1016/S0266-352X(03)00012-0

[10] Pantelidis, L. and Griffiths, D. (2012) Stability Assessment of Slopes Using Different Factoring Strategies. Journal of Geotechnical and Geoenvironmental Engineering, 138, 1158-1160. https://doi.org/10.1061/(ASCE)GT.1943-5606.0000678

[11] Das, B. and Sobhan, K. (2018) Principles of Geotechnical Engineering. 9th Edition, CENGAGE Learning, Boston.

[12] U.S. Army Corps of Engineers (2003) Slope Stability, Engineering and Design, Engineer Manual.

https://www.publications.usace.army.mil/Portals/76/Publications/EngineerManuals /EM 1110-2-1902.pdf

[13] GeoStudio 2012 (2012) Develops Markets and Supports State-of-the-Art CAD Software for Geotechnical and Geo-Environmental Modelling. GEO-SLOPE International Ltd., Calgary. https://info@geo-slope.com.

[14] Hack, R. (2000) Geophysics for Slope Stability. Surveys in Geophysics, 21, 423-448. https://doi.org/10.1023/A:1006797126800

[15] Morgenstern, N.R. and Price, V.E. (1965) The Analysis of the Stability of General Slip Surfaces. Géotechnique, 15, 79-93. https://doi.org/10.1680/geot.1965.15.1.79 